\title{
Purinergic P2 Receptors: Novel Mediators of Mechanotransduction
}

\author{
Qihang Kong ${ }^{1}$, Yue Quan ${ }^{1}$, Geer Tian ${ }^{1}$, Junteng Zhou ${ }^{2}$ and Xiaojing Liu ${ }^{1,2 *}$ \\ ${ }^{1}$ Laboratory of Cardiovascular Diseases, Regenerative Medicine Research Center, West China Hospital, Sichuan University, \\ Chengdu, China, ${ }^{2}$ Department of Cardiology, West China Hospital, Sichuan University, Chengdu, China
}

OPEN ACCESS

Edited by:

Francesco Caciagli,

University of Studies G.d'Annunzio

Chieti and Pescara, Italy

Reviewed by:

Luca Antonioli,

University of Pisa, Italy

Sonja Buvinic,

University of Chile, Chile

Talita Glaser,

University of São Paulo, Brazil

*Correspondence:

Xiaojing Liu

liuxq@scu.edu.cn

Specialty section:

This article was submitted to

Experimental Pharmacology and Drug

Discovery,

a section of the journal

Frontiers in Pharmacology

Received: 24 February 2021

Accepted: 26 April 2021

Published: 07 May 2021

Citation:

Kong Q, Quan Y, Tian G, Zhou J and Liu X (2021) Purinergic P2 Receptors:

Novel Mediators

of Mechanotransduction.

Front. Pharmacol. 12:671809.

doi: 10.3389/fphar.2021.671809
Mechanosensing and mechanotransduction are vital processes in mechanobiology and play critical roles in regulating cellular behavior and fate. There is increasing evidence that purinergic P2 receptors, members of the purinergic family, play a crucial role in cellular mechanotransduction. Thus, information on the specific mechanism of P2 receptormediated mechanotransduction would be valuable. In this review, we focus on purinergic P2 receptor signaling pathways and describe in detail the interaction of P2 receptors with other mechanosensitive molecules, including transient receptor potential channels, integrins, caveolae-associated proteins and hemichannels. In addition, we review the activation of purinergic P2 receptors and the role of various P2 receptors in the regulation of various pathophysiological processes induced by mechanical stimuli.

Keywords: purinergic P2 receptors, mechanical stress, nucleotides, cellular mechanotransduction, mechanoreceptors

\section{INTRODUCTION}

Mechanotransduction refers to the conversion by cells of external mechanical signals into internal biochemical signals (Maurer and Lammerding, 2019). Mechanotransduction enables living organisms to sense a range of mechanical stimuli, including shear stress, stretch-induced strain and osmotic pressure (Wang et al., 2019). Mechanosensors are an important class of molecules that directly and rapidly convert mechanical signals into biochemically relevant signals (Cox et al., 2019). Activation of mechanosensors is the first step in mechanotransduction. There are extensive reviews on mechanotransduction and the ways in which mechanical forces regulate cellular function $\mathrm{Wu}$ et al., 2018; Ozkale et al., 2020). An increasing body of evidence indicates that purinergic P2 receptors (P2Rs) are involved in multiple mechanotransduction pathways.

P2Rs are specialized membrane receptors, which are ubiquitously expressed in various cells and induce biological effects by selectively combining with extracellular nucleotides, such as tri-phosphate nucleosides and di-phosphate nucleosides (Coddou et al., 2011; Di Virgilio et al., 2018). P2Rs encompass a complex network of membrane receptors, including P2X purinergic receptors (P2XRs) and P2Y purinergic receptors (P2YRs). P2XRs are ligand-gated ion channels, while P2YRs are members of sevenmembrane-spanning G protein-coupled receptors. Based on differences in their structural and functional characteristics, P2XRs and P2YRs are further subdivided into seven P2X (1-7) subtypes and eight P2Y (1, 2, 4, 6, 11-14) subtypes, respectively (Antonioli et al., 2019).

Adenosine triphosphate (ATP) release and subsequent activation of purinergic receptors are critical in mechanotransduction (Moehring et al., 2018). Cells can directly respond to mechanical stress in the extracellular environment through $\mathrm{G}$ protein-coupled receptors and mechanosensitive cation channels (Kefauver et al., 2020; Marullo et al., 2020). In this review, we summarize recent findings on P2R-mediated mechanotransduction and review the role of P2Rs in mechanical forcemediated pathophysiological process. 


\section{MECHANISMS OF P2RS AS MECHANOTRANSDUCERS}

The response of cells to mechanical stimuli involves activation of P2Rs and subsequent initiation of intracellular downstream signaling. Elucidation of the mechanisms underlying P2Rsmediated mechanotransduction could shed light on the optimum approach to target P2Rs in the clinical setting. Multiple mechanosensitive molecules, including transient receptor potential (TRP) channels, integrins, caveolaeassociated proteins, hemichannels and piezo1, have been identified that are involved in P2Rs-mediated mechanotransduction.

\section{Interactions of P2Rs With TRP Channels}

The TRP channel family is a type of tetrameric complex located mainly in the plasma membrane, which can be activated directly by a mechanical stimulus (Liu and Montell, 2015; Haustrate et al., 2020). There is evidence supporting mechanical signals inducing interactions between TRP channels and P2Rs, which is mainly reflected in ATP release-mediated coupling of them. For example, in gastrointestinal epithelia, stretch-induced activation of transient receptor potential vanilloid 4 (TRPV4) triggers vesicular nucleotide transporter (VNUT)-mediated ATP exocytosis and increases plasma membrane permeability, resulting in ATP release. ATP release then leads to the activation of P2Rs, and further regulates the production of visceral pain. These findings imply that TRPV4 plays an essential role in P2Rs activation (Mihara et al., 2020). An interaction between transient receptor potential vanilloid 1 (TRPV1) and P2XRs in bladder afferent neurons also appears to be essential for the mechanotransduction during bladder filling (Grundy et al., 2018). Thus, TRPV1 may play a role in mediating bladder mechanosensitivity.

Moreover, in an experiment on cutaneous wound healing, ATP release triggered by mechanical stress activated P2Y2R, which induced long-lasting $\mathrm{Ca}^{2+}$ influx into keratinocytes through transient receptor potential canonical 6 (TRPC6) (Takada et al., 2014). In another study, under the action of fluid, endogenously released ATP affected the opening of the TRPV4 and transient receptor potential canonical 1 (TRPC1) by activating $\mathrm{P} 2 \mathrm{X} 4 \mathrm{R}$, thereby regulating the intracellular $\mathrm{Ca}^{2+}$ concentration of endothelial cells ( $\mathrm{Li}$ et al., 2015). Thus, current research strongly suggests that interactions between TRP channels and P2Rs regulate mechanosensory signal transduction. However, as apparent in these studies, P2Rs are not intrinsically mechanosensitive. Whether other interactions between P2Rs and TRP channels exist that do not depend on ATP deserves further study. Studies on the conformation and distribution of P2Rs and TRP channels could shed light on other potential protein-protein interactions.

\section{Interactions of P2Rs With Integrins}

The integrin family forms integrin adhesion sites with various enzymes and membrane-associated proteins located between the extracellular matrix and the cytoskeleton (Osugi et al., 2019). These adhesion sites are essential for integrin-dependent cell adhesion, proliferation, migration and survival (Nolte and Margadant, 2020). A remarkable feature of integrin-mediated adhesion is mechanosensitivity (Sun et al., 2016).

Based on the membrane colocalization of P2Rs and integrins, Cabahug-Zuckerman et al. utilized immunohistochemistry combined with structured illumination super-resolution microscopy for further exploration and then they observed the 'osteocyte mechanical body', a specialized mechanotransduction complex, which composed of pannexin 1, P2X7R, T-type $\mathrm{Ca}^{2+}$ channel and $\alpha_{V} \beta_{3}$ integrins (Cabahug-Zuckerman et al., 2018). The presence of this specialized mechanotransduction complex may help to explain the remarkable mechanosensitivity of osteocytes. Such unique mechanotransduction mediated by $\mathrm{P} 2 \mathrm{X} 7 \mathrm{R}$ and $\alpha_{\mathrm{V}} \beta 3$ integrin also appears to be an ATP-based signaling pathway. As P2X7R may mediate the release of ATP (Johnsen et al., 2019), it is necessary to identify the source of ATP. Previous research has also shed light on the role of interactions between P2Y2R and $\alpha_{V} \beta_{3 / 5}$ integrins in human umbilical vein endothelial cells. Differed from the ATP-based way, the novel spot focused on the Arg-Gly-Asp integrin-binding domain in this research. This domain directly mediates the coupling of P2Y2R and $\alpha_{V} \beta_{3 / 5}$ integrins. Subsequently, integrin signaling pathways mediated by P2Y2R activate cofilin-1, which modulates shear stress-induced endothelial cytoskeletal alterations, wound closure, and cell alignment (Sathanoori et al., 2017).

As is clear from the above, the interplay between integrins and $\mathrm{P} 2 \mathrm{R}$ is vital in maintaining mechanotransduction. Investigations of P2X7R-mediated ATP release are important because both the ligand required for $\mathrm{P} 2 \mathrm{X} 7 \mathrm{R}$ and the substance it releases may be ATP. Furthermore, analyses of protein-protein interaction domains of $\mathrm{P} 2 \mathrm{Y} 2 \mathrm{R}$ and integrins may reveal potential targets for drug therapy.

\section{Interaction of P2Rs With Caveolae-Associated Proteins}

Caveolae-associated proteins, such as caveolin-1 (Cav-1), caveolin-2 (Cav-2) and caveolin-3 (Cav-3), are essential for the formation and maintenance of the structure of caveolae in cell membranes (Low and Nicholson, 2015). As one of the main raft scaffolding proteins, Cav-1 is involved in mechanotransduction by coupling membrane-bound receptors to downstream signaling molecules (Martinez et al., 2016). Existing evidence points to an important role for Cav-1 in P2R-mediated mechanotransduction. For example, when enterochromaffin cells are mechanically stimulated, Cav-1 associated with cholesterol-rich microdomains in caveolae forms a scaffold to support the activation of P2Y1R, subsequently leading to the release of 5hydroxytryptamine (5-HT), which is involved in mucosal secretory reflexes, motility and transmission of information related to visceral pain sensations (Linan-Rico et al., 2016). A recent study using a mechanical injury model system revealed the presence of P2Y2R in Cav-1 raft micro-domains of astrocytoma cells (Martinez et al., 2019). In this study, Cav-1 modulated the cell survival rate by regulating Akt and ERK1/2 phosphorylation, mediated by P2Y2R. The resulting scaffold formed by Cav-1 is essential for P2Y2R signaling. Moreover, P2Y2R and Cav-1 also 
play a functional role in alveoli via ATP-dependent way, resulting in the regulation of surfactant secretion. Noteworthy, P2Y2R does not exist in the scaffold formed by Cav-1. In this process, in response to mechanical distension, ATP release from alveolar type I cells stimulates exocytosis of lamellar bodies of alveolar type II cells by increasing the intracellular $\mathrm{Ca}^{2+}$ level (Diem et al., 2020).

The interaction of Cav-1 with P2XRs has been previously reported, including Cav-1 acting as a regulatory switch to ensure the efficient activity of P2Rs. In osteoblasts, Cav-1 attenuates P2X7R-mediated mechanotransduction via endocytosis. During this process, Cav-1 detaches from P2X7R and is transported to the cytoplasm (Gangadharan et al., 2015). Additionally, shear stress seems to induce mitochondrial ATP generation of endothelial cells through Cav-1. ATP-mediated P2X4R activation then evokes a $\mathrm{Ca}^{2+}$ wave (Yamamoto et al., 2018). In terms of the interaction between Cav-1 and P2Rs, there has been little study on the contact sites or domains between Cav-1 and P2Rs. More research is needed to provide evidence of a direct relation between Cav-1 and P2Rs.

\section{Functional Interplay of P2Rs With Pannexin and Connexin Hemichannels}

There is compelling evidence to support a crucial role of ATP release-mediated coupling of mechanosensitive hemichannels and P2Rs in mechanotransduction. The pannexin family is a class of channel-forming proteins that form large, non-selective plasma membrane channels, which enable the movement of molecules and ions (Chiu et al., 2018; Michalski et al., 2020). The pannexin 1-P2X7R signaling complex is important in mechanotransduction in bone and urinary system (Negoro et al., 2014; Seref-Ferlengez et al., 2016). A pannexin 1dependent mechanosensitive mechanism modulates ATP signaling and is essential for load-induced skeletal responses and transmission of bladder wall distension signaling (Negoroet al., 2014; Seref-Ferlengez et al., 2019). Under mechanical stretch applied to atrial myocytes, ATP released by pannexin 2 activates $\mathrm{P} 2 \mathrm{Rs}$ to induce macrophage migration (Oishi et al., 2012). However, the identity of the specific P2Rs involved in the aforementioned processes remains unknown. In addition, a pannexin 1-dependent mechanosensitive mechanism that modulates P2YRs rather than P2XRs promoted the survival of metastatic cells during the process of intravascular deformation induced by membrane stretch (Furlow et al., 2015).

Connexins, in particular connexin 43, are post-translational phosphorylated proteins involved in mechanotransduction (Plotkin et al., 2015; Delvaeye et al., 2018). P2Rs are known to be involved in connexin channel-dependent mechanotransduction. For instance, in human periodontal ligament cells, continuous compressive forces induce ATP release from connexin 43. During this process, ATP increases the expression and the synthesis of osteopontin and receptor activator of nuclear factor $\mathrm{kB}$ ligand by binding to P2Rs (Luckprom et al., 2011). Similarly, in response to mechanical loading, connexin 43-dependent ATP release in chondrocyte accelerated the synthesis of proteoglycan by activating P2Rs (Garcia and Knight, 2010). Coupling of P2Rs and other connexin family members mediated by ATP release has been demonstrated (Svenningsen et al., 2013). In this study, ATP release mediated by connexin 30 and subsequent P2Y2R activation played an important role in regulating renal salt and water reabsorption, maintaining fluid and the electrolyte balance and normal blood pressure. In another study, when bovine corneal endothelial cells underwent severe short-term deformation in response to a local mechanical stimulus, connexin 43-dependent ATP release induced the activation of P2Y1R and P2Y2R on plasma membrane of adjacent cells and subsequent $\mathrm{Ca}^{2+}$ wave propagation (Iyyathurai et al., 2016).

As mentioned above, coupling of the hemichannels and P2Rs mediated by ATP release is essential for mechanotransduction. Supplementary Table S1 lists down the key components in the above-mentioned purinergic receptor signaling. Remarkable, the functional characteristics of piezol channels are similar to those of hemichannels, as outlined in a recent comprehensive review (Wei et al., 2019). Despite this similarity, the relationship of mechanically activated cation piezo2 with P2Rs has not been reported. Additionally, as a prominent mechanical cue, extracellular matrix stiffness regulates the chondrogenic response of mesenchymal stem cells to hydrostatic pressure by altering P2Rs sensitivity or by some other mechanism that is downstream of P2Rs activation, although the exact type of P2Rs is still unclear (Steward et al., 2016). Based on the current literature on mechanosensor-mediated activation of the purinergic signaling pathway, extracellular mechanical stimuli cannot induce P2R activation directly. Further work is needed to shed light on the effect of mechanical stimuli on P2Rs.

\section{INVOLVEMENT OF P2RS IN MECHANICAL FORCE MEDIATED PATHOPHYSIOLOGICAL PROCESS}

Mechanical forces, such as shear stress, stretch and microgravity, cause physical deformation of cell structure (Cox et al., 2019), which has been a hotspot in cellular biomechanics for decades. Shear stress is the frictional force exerted on cells by a fluid environment (Klems et al., 2020). Mechanical stretch mainly comes from the distension of organs or tissues. These mechanical forces are common in bone and in the gastrointestinal, circulatory and urinary systems (Miyamoto et al., 2014; Kauffenstein et al., 2016; Linan-Rico et al., 2016; $\mathrm{Xu}$ et al., 2017). The development and morphogenesis of living organisms require the generation of mechanical forces, which is a critical apart of mechanobiology (Yu et al., 2018).

\section{P2Rs-Mediated Mechanotransduction in the Cardiovascular System}

$\mathrm{P} 2 \mathrm{Rs}$ are involved in cardiovascular pathological processes, such as vascular inflammation and atherosclerosis (Wang et al., 2017). As shown in a clinical study, P2Y2R and $G_{q} / G_{11}$ (G proteins) control blood pressure by mediating endothelium mechanotransduction (Wang et al., 2015). Another study reported that exposure of endothelium to disturbed blood flow appears to generate multiple inflammatory signals, including p38 
signaling, E-selectin and Interleukin-8 secretion, which is regulated by ATP-dependent P2X7R (Green et al., 2018). In this process, $\mathrm{P} 2 \mathrm{X} 7 \mathrm{R}$ promotes endothelium inflammation at atheroprone sites by transducing ATP signals into p38 activation. According to the literature, P2X7R might represent a potential therapy for improving endothelial dysfunction and subsequently atherosclerosis. Based on a study on cardiomyocytes, purinergic signaling appears to be related to mechanical stress-induced cardiac fibrosis (Nishida et al., 2008). In this study, pannexin 1-dependent P2Y6R activation in cardiomyocytes induced the expression of fibrogenic factors, which activated cardiac fibroblasts in a paracrine manner. Additionally, in rat atrial myocytes, an increase in $\mathrm{Ca}^{2+}$ influx induced by shear stress during a hemodynamic disturbance was abolished by pharmacological blockade of P2Y1R. Thus, it can be seen that P2Y1R plays an important role in regulation of cardiac contraction (Kim and Woo, 2015).

\section{Regulation of Bone Mechanotransduction by P2Rs}

The mechanical environment in which bone cells are embedded is a dynamic combination of various mechanical stimuli, including shear stress, strain and osmotic pressure (Qin et al., 2020). Like in the cardiovascular system, the shear stress of fluid flow is the main force stimulation applied to osteocytes in bone. The abundance of P2Rs in bone points to their potential role in bone homeostasis (Ottensmeyer et al., 2018).

In a murine calvarial osteoblast MC3T3-E1 cell line, when compressive force was applied to MC3T3-E1 cells by centrifugation, the pressure increased extracellular ATP via induction of VNUT (Inoue et al., 2020). Subsequently, VNUTmediated ATP release inhibited osteoblast differentiation through $\mathrm{P} 2 \mathrm{X} 7 \mathrm{R}$ and/or P2Y2R. A recent study also reported that P2Y14R, the only P2YR stimulated by uridine diphosphate sugars, contributed to the differentiation of osteoblasts under a mechanical stimulus, which was confirmed in primary murine osteoblasts and a C2C12-BMP2 osteoblastic cell line (Mikolajewicz and Komarova, 2020). Another study indicated that ATP release induced by low-intensity pulsed ultrasound promotes osteoblast proliferation and osteogenic responses via the activation of P2X7R (Manaka et al., 2015). In addition, $\mathrm{P} 2 \mathrm{Y} 13 \mathrm{R}$ contributes to mediation of osteogenic responses to mechanical loading by regulating ATP metabolism in osteoblasts (Wang et al., 2013). Based on a micro-CT analysis of osteoclasts from $\mathrm{P} 2 \mathrm{Y} 2 \mathrm{R}^{-1-}$ mice, activation of $\mathrm{P} 2 \mathrm{Y} 2 \mathrm{R}$ under mechanical loading regulates bone resorption and mineralization by enhancing ATP release (Orriss et al., 2017).

\section{Roles of P2Rs in Other Pathophysiological Processes}

P2Rs are activated in other organs and systems, such as the gastrointestinal system and bladder. For example, endogenous ATP released after abnormal intestinal wall extension induces visceral pain by activating $\mathrm{P} 2 \mathrm{X} 2 \mathrm{R}$ and $\mathrm{P} 2 \mathrm{X} 3 \mathrm{R}$ on nociceptive neurons (Wynn et al., 2004). In the process of mucosal stroking reflex of the guinea pig distal colon, 5-HT activates intrinsic primary afferent neurons, and ATP release activates P2Y1R on secretomotor cholinergic neurons, leading to an increase in short circuit current/ chloride ion secretion (Cooke et al., 2004). Unlike the aforementioned model, in the touch/stretch reflex of the distal colon of rats, 5-HT release caused activation of P2Y1R, P2Y2R and $\mathrm{P} 2 \mathrm{Y} 4 \mathrm{R}$, resulting in a net increase in chloride secretion (Christofi et al., 2004). P2Y1R also seems to play a major role in increasing 5HT levels in response to a mechanical stimulus of the ileum mucosal epithelium of the guinea pig (Patel, 2014). Interestingly, in this research, the P2Rs inhibitor had no impact on 5-HT levels in the distal colon. This finding is likely due to differences in interactions between 5-HT and P2Rs in different regions of the gastrointestinal tract. Elucidating the underlying mechanism will benefit our understanding of gastrointestinal tract signaling. In addition, a study has shown that P2X3R plays an important role in colon mechanotransduction and hypersensitivity (Shinoda et al., 2009). However, the specific mechanism of action of P2X3R remains to be confirmed.

During bladder filling, ATP release and subsequent P2YRs activation mediates the storage capacity of the urinary bladder in response to membrane stretch, indicating the importance of P2YRs to the physiological function of the bladder (Mansfield and Hughes, 2014). When urothelial cells are stretched, ATPdependent P2Rs activation leads to the release of $\mathrm{Ca}^{2+}$, thereby preventing an overactive bladder and fecal incontinence (Guan et al., 2018). In mice, the absence of P2Y6R in dorsal root ganglia leads to an increase in the afferent sensitivity of traction stimulation signals, resulting in frequent micturition and a decrease in bladder capacity (Kira et al., 2017).

From a functionality point of view, these literatures point to a key role for P2Rs as mechanotransducers in multiple organs and systems. Supplementary Figure S1 illustrates a proposed relationship between P2Rs and mechanosensitive molecules, and P2Rs mediated-pathophysiological process. Antagonists or agonists of P2YRs are widely used to treat various diseases, such as dry eye syndrome and inflammation (Jacobson et al., 2020). However, the lack of availability of selective agonists for P2XRs remains a problem (Illes et al., 2021). Moreover, given that most drugs still being tested in preclinical experiments, rigorous clinical investigations and subsequent development of new medications targeting P2Rs are required.

\section{CONCLUSION}

In response to extracellular mechanical stimulus, the interaction of P2Rs with TRP channels, integrins, Cav-1 or hemichannels initiates complex signaling cascades, contributing to changes in the pathophysiological state. Therefore, targeting P2Rs, offers great promise as a novel therapeutic strategy in dysregulated mechanotransduction. Significant advancements have deepened our understanding of the structure and functions of P2Rs in mechanotransduction. Activation of P2Rs seems to be a downstream event caused by the release of nucleotides 
exposed to a mechanical stimulus. The potential function of P2Rs as direct mechanosensors needs further research. Fortunately, the widespread availability of single-molecule localization microscopy in the area of sub-cellular structures means it is now possible to study interactions between membrane channel proteins and their accessory subunits (Stone et al., 2017). Such studies hold promise in shedding light on the study of the interaction between P2Rs and mechanosensitive molecules.

Future directions for research include studies on:1) the potential role of mechanical stress in direct activation P2Rs, independently of chemical agonists; 2) the protein-protein interaction domains between P2Rs and mechanosensors; 3) ATP release-mediated coupling of the mechanosensitive ion channel piezo2 and P2Rs; 4) the relationship between extracellular matrix stiffness and P2Rs; 5) the role of other $\mathrm{P} 2 \mathrm{Rs}$ in mechanotransduction, such as P2X6R, P2Y11R and $\mathrm{P} 2 \mathrm{Y} 12 \mathrm{R} ; 6)$ and the development and testing of drugs that target P2Rs in mechanotransduction.

\section{REFERENCES}

Antonioli, L., Blandizzi, C., Pacher, P., and Haskó, G. (2019). The Purinergic System as a Pharmacological Target for the Treatment of Immune-Mediated Inflammatory Diseases. Pharmacol. Rev. 71, 345-382. doi:10.1124/pr.117. 014878

Cabahug-Zuckerman, P., Stout, R. F., Jr., Majeska, R. J., Thi, M. M., Spray, D. C., Weinbaum, S., et al. (2018). Potential Role for a Specialized $\beta 3$ integrin-based Structure on Osteocyte Processes in Bone Mechanosensation. J. Orthop. Res. 36, 642-652. doi:10.1002/jor.23792

Chiu, Y.-H., Schappe, M. S., Desai, B. N., and Bayliss, D. A. (2018). Revisiting Multimodal Activation and Channel Properties of Pannexin 1. J. Gen. Physiol. Jan 150, 19-39. doi:10.1085/jgp.201711888

Christofi, F. L., Wunderlich, J., Yu, J. G., Wang, Y.-Z., Xue, J., Guzman, J., et al. (2004). Mechanically Evoked Reflex Electrogenic Chloride Secretion in Rat Distal Colon Is Triggered by Endogenous Nucleotides Acting at P2Y1, P2Y2, and P2Y4 Receptors. J. Comp. Neurol. 469, 16-36. doi:10. 1002/cne.10961

Coddou, C., Yan, Z., Obsil, T., Huidobro-Toro, J. P., and Stojilkovic, S. S. (2011). Activation and Regulation of Purinergic P2X Receptor Channels. Pharmacol. Rev. 63, 641-683. doi:10.1124/pr.110.003129

Cooke, H. J., Xue, J., Yu, J. G., Wunderlich, J., Wang, Y.-Z., Guzman, J., et al. (2004). Mechanical Stimulation Releases Nucleotides that Activate P2Y1 Receptors to Trigger Neural Reflex Chloride Secretion in guinea Pig Distal Colon. J. Comp. Neurol. 469, 1-15. doi:10.1002/cne.10960

Cox, C. D., Bavi, N., and Martinac, B. (2019). Biophysical Principles of IonChannel-Mediated Mechanosensory Transduction. Cel Rep. 29, 1-12. doi:10. 1016/j.celrep.2019.08.075

Delvaeye, T., Vandenabeele, P., Bultynck, G., Leybaert, L., and Krysko, D. V. (2018). Therapeutic Targeting of Connexin Channels: New Views and Challenges. Trends Mol. Med. 24, 1036-1053. doi:10.1016/j.molmed.2018. 10.005

Di Virgilio, F., Sarti, A. C., Falzoni, S., De Marchi, E., and Adinolfi, E. (2018). Extracellular ATP and P2 Purinergic Signalling in the Tumour Microenvironment. Nat. Rev. Cancer 18, 601-618. doi:10.1038/s41568-0180037-0

Diem, K., Fauler, M., Fois, G., Hellmann, A., Winokurow, N., Schumacher, S., et al. (2020). Mechanical Stretch Activates Piezol in Caveolae of Alveolar Type I Cells to Trigger ATP Release and Paracrine Stimulation of Surfactant Secretion from Alveolar Type II Cells. FASEB J. 34, 12785-12804. doi:10.1096/fj. 202000613RRR

\section{AUTHOR CONTRIBUTIONS}

QK drafted the manuscript. YQ, GT, and JZ revised the manuscript. XL edited the manuscript. All authors read and approved the final manuscript.

\section{FUNDING}

This work was supported by the National Natural Science Foundation of China (No. 12072215, 11672197 by XL).

\section{SUPPLEMENTARY MATERIAL}

The Supplementary Material for this article can be found online at: https://www.frontiersin.org/articles/10.3389/fphar.2021.671809/ full\#supplementary-material

Furlow, P. W., Zhang, S., Soong, T. D., Halberg, N., Goodarzi, H., Mangrum, C., et al. (2015). Mechanosensitive Pannexin-1 Channels Mediate Microvascular Metastatic Cell Survival. Nat. Cel Biol 17, 943-952. doi:10.1038/ncb3194

Gangadharan, V., Nohe, A., Caplan, J., Czymmek, K., and Duncan, R. L. (2015). Caveolin-1 Regulates P2X7 Receptor Signaling in Osteoblasts. Am. J. Physiol. Cell Physiol. 308, C41-C50. doi:10.1152/ajpcell.00037.2014

Garcia, M., and Knight, M. M. (2009). Cyclic Loading Opens Hemichannels to Release ATP as Part of a Chondrocyte Mechanotransduction Pathway. J. Orthop. Res. 28, 510-515. doi:10.1002/jor.21025

Green, J. P., Souilhol, C., Xanthis, I., Martinez-Campesino, L., Bowden, N. P., Evans, P. C., et al. (2018). Atheroprone Flow Activates Inflammation via Endothelial ATP-dependent P2X7-P38 Signalling. Cardiovasc. Res. 114, 324-335. doi:10.1093/cvr/cvx213

Grundy, L., Daly, D. M., Chapple, C., Grundy, D., and Chess-Williams, R. (2018). TRPV1 Enhances the Afferent Response to P2X Receptor Activation in the Mouse Urinary Bladder. Sci. Rep. 8 (8), 197. doi:10. 1038/s41598-017-18136-w

Guan, N. N., Sharma, N., Hallén-Grufman, K., Jager, E. W. H., and Svennersten, K. (2018). The Role of ATP Signalling in Response to Mechanical Stimulation Studied in T24 Cells Using New Microphysiological Tools. J. Cel. Mol. Med. 22, 2319-2328. doi:10.1111/jcmm.13520

Haustrate, A., Prevarskaya, N., and Lehen'kyi, V. y. (2020). Role of the TRPV Channels in the Endoplasmic Reticulum Calcium Homeostasis. Cells 9, 317. doi: $10.3390 /$ cells 9020317

Illes, P., Müller, C. E., Jacobson, K. A., Grutter, T., Nicke, A., Fountain, S. J., et al. (2021). Update of P2X Receptor Properties and Their Pharmacology: IUPHAR Review 30. Br. J. Pharmacol. 178, 489-514. doi:10.1111/bph.15299

Inoue, A., Nakao-Kuroishi, K., Kometani-Gunjigake, K., Mizuhara, M., Shirakawa, T., Ito-Sago, M., et al. (2020). VNUT/SLC17A9, a Vesicular Nucleotide Transporter, Regulates Osteoblast Differentiation. Febs Open Bio 10, 1612-1623. doi:10.1002/2211-5463.12918

Iyyathurai, J., Himpens, B., Bultynck, G., and D’hondt, C. (2016). Calcium Wave Propagation Triggered by Local Mechanical Stimulation as a Method for Studying Gap Junctions and Hemichannels. Methods Mol. Biol. 1437, 203-211. doi:10.1007/978-1-4939-3664-9_15

Jacobson, K. A., Delicado, E. G., Gachet, C., Kennedy, C., Kügelgen, I., Li, B., et al. (2020). Update of P2Y Receptor Pharmacology: IUPHAR Review 27. Br. J. Pharmacol. 177, 2413-2433. doi:10.1111/bph.15005

Johnsen, B., Kaschubowski, K. E., Nader, S., Schneider, E., Nicola, J.-A., Fliegert, R., et al. (2019). P2X7-mediated ATP Secretion Is Accompanied by Depletion of Cytosolic ATP. Purinergic Signal. 15, 155-166. doi:10.1007/s11302-01909654-5 
Kauffenstein, G., Tamareille, S., Prunier, F., Roy, C., Ayer, A., Toutain, B., et al. (2016). Central Role of P2Y 6 UDP Receptor in Arteriolar Myogenic Tone. Arterioscler Thromb. Vasc. Biol. 36, 1598-1606. doi:10.1161/ATVBAHA.116. 307739

Kefauver, J. M., Ward, A. B., and Patapoutian, A. (2020). Discoveries in Structure and Physiology of Mechanically Activated Ion Channels. Nature 587, 567-576. doi:10.1038/s41586-020-2933-1

Kim, J.-C., and Woo, S.-H. (2015). Shear Stress Induces a Longitudinal Ca2+wave via Autocrine Activation of P2Y1purinergic Signalling in Rat Atrial Myocytes. J. Physiol. 593, 5091-5109. doi:10.1113/Jp271016

Kira, S., Yoshiyama, M., Tsuchiya, S., Shigetomi, E., Miyamoto, T., Nakagomi, H., et al. (2017). P2Y6-deficiency Increases Micturition Frequency and Attenuates Sustained Contractility of the Urinary Bladder in Mice. Sci. Rep. 7, 771. doi:10. 1038/s41598-017-00824-2

Klems, A., van Rijssel, J., Ramms, A. S., Wild, R., Hammer, J., Merkel, M., et al. (2020). The GEF Trio Controls Endothelial Cell Size and Arterial Remodeling Downstream of Vegf Signaling in Both Zebrafish and Cell Models. Nat. Commun. 11, 5319. doi:10.1038/s41467-020-19008-0

Li, L. F., Xiang, C., and Qin, K. R. (2015). Modeling of TRPV(4)-C(1)-Mediated Calcium Signaling in Vascular Endothelial Cells Induced by Fluid Shear Stress and ATP. Biomech. Model. Mechanobiol. 14, 979-993. doi:10.1007/s10237-0150647-3

Linan-Rico, A., Ochoa-Cortes, F., Beyder, A., Soghomonyan, S., Zuleta-Alarcon, A., Coppola, V., et al. (2016). Mechanosensory Signaling in Enterochromaffin Cells and 5-HT Release: Potential Implications for Gut Inflammation. Front. Neurosci. 10, 564. doi:10.3389/fnins.2016.00564

Liu, C., and Montell, C. (2015). Forcing Open TRP Channels: Mechanical Gating as a Unifying Activation Mechanism. Biochem. Biophysical Res. Commun. 460 (460), 22-25. doi:10.1016/j.bbrc.2015.02.067

Low, J.-Y., and Nicholson, H. D. (2015). Epigenetic Modifications of Caveolae Associated Proteins in Health and Disease. BMC Genet. 16, 71. doi:10.1186/ s12863-015-0231-y

Luckprom, P., Kanjanamekanant, K., and Pavasant, P. (2011). Role of Connexin43 Hemichannels in Mechanical Stress-Induced ATP Release in Human Periodontal Ligament Cells. J. Periodontal Res. Oct 46, 607-615. doi:10. 1111/j.1600-0765.2011.01379.x

Manaka, S., Tanabe, N., Kariya, T., Naito, M., Takayama, T., Nagao, M., et al. (2015). Low-intensity Pulsed Ultrasound-Induced ATP Increases Bone Formation via the P2X7 Receptor in Osteoblast-like MC3T3-E1 Cells. Febs Lett. Jan 589, 310-318. doi:10.1016/j.febslet.2014.12.013

Mansfield, K. J., and Hughes, J. R. (2014). P2Y Receptor Modulation of ATP Release in the Urothelium. Biomed. Res. Int. 2014, 1-8. doi:10.1155/2014/ 830374

Martínez, M., Martínez, N. A., Miranda, J. D., Maldonado, H. M., and Silva Ortiz, W. I. (2019). Caveolin-1 Regulates P2Y2 Receptor Signaling during Mechanical Injury in Human 1321N1 Astrocytoma. Biomolecules 9, 622. doi:10.3390/ biom9100622

Martinez, N. A., Ayala, A. M., Martinez, M., Martinez-Rivera, F. J., Miranda, J. D., and Silva, W. I. (2016). Caveolin-1 Regulates the P2Y2 Receptor Signaling in Human 1321N1 Astrocytoma Cells. J. Biol. Chem. 291, 12208-12222. doi:10. 1074/jbc.M116.730226

Marullo, S., Doly, S., Saha, K., Enslen, H., Scott, M. G. H., and Coureuil, M. (2020). Mechanical GPCR Activation by Traction Forces Exerted on ReceptorNGlycans. ACS Pharmacol. Transl. Sci. 3 (3), 171-178. doi:10.1021/acsptsci. $9 \mathrm{~b} 00106$

Maurer, M., and Lammerding, J. (2019). The Driving Force: Nuclear Mechanotransduction in Cellular Function, Fate, and Disease. Annu. Rev. Biomed. Eng. 21 (21), 443-468. doi:10.1146/annurev-bioeng-060418-052139

Michalski, K., Syrjanen, J. L., Henze, E., Kumpf, J., Furukawa, H., and Kawate, T. (2020). The Cryo-EM Structure of Pannexin 1 Reveals Unique Motifs for Ion Selection and Inhibition. Elife 9, e54670. doi:10.7554/eLife.54670

Mihara, H., Boudaka, A., Tominaga, M., and Sugiyama, T. (2020). Transient Receptor Potential Vanilloid 4 Regulation of Adenosine Triphosphate Release by the Adenosine Triphosphate Transporter Vesicular Nucleotide Transporter, a Novel Therapeutic Target for Gastrointestinal Baroreception and Chronic Inflammation. Digestion 101, 6-11. doi:10.1159/000504021

Mikolajewicz, N., and Komarova, S. V. (2020). Role of UDP-Sugar Receptor P2Y14 in Murine Osteoblasts. Ijms 21, 2747. doi:10.3390/ijms21082747
Miyamoto, T., Mochizuki, T., Nakagomi, H., Kira, S., Watanabe, M., Takayama, Y., et al. (2014). Functional Role for Piezol in Stretch-Evoked Ca2+ Influx and ATP Release in Urothelial Cell Cultures. J. Biol. Chem. 289, 16565-16575. doi:10.1074/jbc.M113.528638

Moehring, F., Cowie, A. M., Menzel, A. D., Weyer, A. D., Grzybowski, M., Arzua, T., et al. (2018). Keratinocytes Mediate Innocuous and Noxious Touch via ATPP2x4 Signaling. Elife 7, e31684. doi:10.7554/eLife.31684

Negoro, H., Urban-Maldonado, M., Liou, L. S., Spray, D. C., Thi, M. M., and Suadicani, S. O. (2014). Pannexin 1 Channels Play Essential Roles in Urothelial Mechanotransduction and Intercellular Signaling. PLoS One 9, e106269. doi:10. 1371/journal.pone.0106269

Nishida, M., Sato, Y., Uemura, A., Narita, Y., Tozaki-Saitoh, H., Nakaya, M., et al. (2008). P2Y6 Receptor-Ga12/13 Signalling in Cardiomyocytes Triggers Pressure Overload-Induced Cardiac Fibrosis. Embo J. 27, 3104-3115. doi:10. 1038/emboj.2008.237

Nolte, M., and Margadant, C. (2020). Controlling Immunity and Inflammation through Integrin-dependent Regulation of TGF- $\beta$. Trends Cel Biol. 30, 49-59. doi:10.1016/j.tcb.2019.10.002

Oishi, S., Sasano, T., Tateishi, Y., Tamura, N., Isobe, M., and Furukawa, T. (2012). Stretch of Atrial Myocytes Stimulates Recruitment of Macrophages via ATP Released through Gap-Junction Channels. J. Pharmacol. Sci. 120, 296-304. doi:10.1254/jphs.12202FP

Orriss, I. R., Guneri, D., Hajjawi, M. O. R., Shaw, K., Patel, J. J., and Arnett, T. R. (2017). Activation of the P2Y2 Receptor Regulates Bone Cell Function by Enhancing ATP Release. J. Endocrinol. Jun 233, 341-356. doi:10.1530/joe-170042

Osugi, Y., Fumoto, K., and Kikuchi, A. (2019). CKAP4 Regulates Cell Migration via the Interaction with and Recycling of Integrin. Mol. Cel Biol 39, e00073. doi:10. 1128/MCB.00073-19

Ottensmeyer, P., Witzler, M., Schulze, M., and Tobiasch, E. (2018). Small Molecules Enhance Scaffold-Based Bone Grafts via Purinergic Receptor Signaling in Stem Cells. Ijms 19, 3601. doi:10.3390/ijms19113601

Özkale, B., Sakar, M. S., and Mooney, D. J. (2021). Active Biomaterials for Mechanobiology. Biomaterials 267, 120497. doi:10.1016/j.biomaterials.2020. 120497

Patel, B. A. (2014). Mucosal Adenosine Triphosphate Mediates Serotonin Release from Ileal but Not Colonic guinea Pig Enterochromaffin Cells. Neurogastroenterol. Motil. 26, 237-246. doi:10.1111/nmo.12254

Plotkin, L. I., Speacht, T. L., and Donahue, H. J. (2015). Cx43 and Mechanotransduction in Bone. Curr. Osteoporos. Rep. 13, 67-72. doi:10. 1007/s11914-015-0255-2

Qin, L., Liu, W., Cao, H., and Xiao, G. (2020). Molecular Mechanosensors in Osteocytes. Bone Res. 8, 23. doi:10.1038/s41413-020-0099-y

Sathanoori, R., Bryl-Gorecka, P., Müller, C. E., Erb, L., Weisman, G. A., Olde, B., et al. (2017). P2Y2 Receptor Modulates Shear Stress-Induced Cell Alignment and Actin Stress Fibers in Human Umbilical Vein Endothelial Cells. Cell. Mol. Life Sci. 74, 731-746. doi:10.1007/s00018-016-2365-0

Seref-Ferlengez, Z., Urban-Maldonado, M., Sun, H. B., Schaffler, M. B., Suadicani, S. O., and Thi, M. M. (2019). Role of Pannexin 1 Channels in Load-Induced Skeletal Response. Ann. N. Y Acad. Sci. 1442, 79-90. doi:10.1111/nyas.13914

Seref-Ferlengez, Z., Maung, S., Schaffler, M. B., Spray, D. C., Suadicani, S. O., and Thi, M. M. (2016). P2X7R-Panx1 Complex Impairs Bone Mechanosignaling under High Glucose Levels Associated with Type-1 Diabetes. PLoS One 11, e0155107. doi:10.1371/journal.pone.0155107

Shinoda, M., Feng, B., and Gebhart, G. F. (2009). Peripheral and Central P2X3 Receptor Contributions to Colon Mechanosensitivity and Hypersensitivity in the Mouse. Gastroenterol. 137, 2096-2104. doi:10.1053/j.gastro.2009. 06.048

Steward, A. J., Kelly, D. J., and Wagner, D. R. (2016). Purinergic Signaling Regulates the Transforming Growth Factor-B3-Induced Chondrogenic Response of Mesenchymal Stem Cells to Hydrostatic Pressure. Tissue Eng. A 22, 831-839. doi:10.1089/ten.TEA.2015.0047

Stone, M. B., Shelby, S. A., and Veatch, S. L. (2017). Super-Resolution Microscopy: Shedding Light on the Cellular Plasma Membrane. Chem. Rev. 117, 7457-7477. doi:10.1021/acs.chemrev.6b00716

Sun, Z., Guo, S. S., and Fässler, R. (2016). Integrin-mediated Mechanotransduction. J. Cel Biol. Nov 215 (4), 445-456. doi:10.1083/jcb.201609037 
Svenningsen, P., Burford, J. L., and Peti-Peterdi, J. (2013). ATP Releasing Connexin 30 Hemichannels Mediate Flow-Induced Calcium Signaling in the Collecting Duct. Front. Physiol. 4, 292. doi:10.3389/fphys.2013.00292

Takada, H., Furuya, K., and Sokabe, M. (2014). Mechanosensitive ATP Release from Hemichannels and Ca2+ Influx through TRPC6 Accelerate Wound Closure in Keratinocytes. J. Cel Sci. 127, 4159-4171. doi:10.1242/jcs.147314

Wang, J., Wu, Y., Zhang, X., Zhang, F., Lü, D., Shangguan, B., et al. (2019). Flowenhanced Priming of hESCs through H2B Acetylation and Chromatin Decondensation. Stem Cel Res Ther 10 (10), 349. doi:10.1186/s13287-0191454-z

Wang, N., Rumney, R. M., Yang, L., Robaye, B., Boeynaems, J.-M., Skerry, T. M., et al. (2013). The P2Y13receptor Regulates Extracellular ATP Metabolism and the Osteogenic Response to Mechanical Loading. J. Bone Miner Res. 28, 1446-1456. doi:10.1002/jbmr.1877

Wang, Q., Wu, S., Zhu, H., Ding, Y., Dai, X., Ouyang, C., et al. (2017). Deletion of PRKAA Triggers Mitochondrial Fission by Inhibiting the Autophagydependent Degradation of DNM1L. Autophagy 13, 404-422. doi:10.1080/ 15548627.2016.1263776

Wang, S., Iring, A., Strilic, B., Albarrán Juárez, J., Kaur, H., Troidl, K., et al. (2015). P2Y2 and Gq/G11 Control Blood Pressure by Mediating Endothelial Mechanotransduction. J. Clin. Invest. 125, 3077-3086. doi:10.1172/Jci81067

Wei, L., Mousawi, F., Li, D., Roger, S., Li, J., Yang, X., et al. (2019). Adenosine Triphosphate Release and P2 Receptor Signaling in Piezol Channel-dependent Mechanoregulation. Front. Pharmacol. 10, 1304. doi:10.3389/fphar.2019.01304

Wu, C., Shen, Y., Chen, M., Wang, K., Li, Y., and Cheng, Y. (2018). Recent Advances in Magnetic-Nanomaterial-Based Mechanotransduction for Cell Fate Regulation. Adv. Mater. 30, e1705673. doi:10.1002/adma.201705673
Wynn, G., Ma, B., Ruan, H. Z., and Burnstock, G. (2004). Purinergic Component of Mechanosensory Transduction Is Increased in a Rat Model of Colitis. Am. J. Physiol. Gastrointestinal Liver Physiol. 287, G647-G657. doi:10.1152/ajpgi. 00020.2004

Xu, H., Liu, R., Ning, D., Zhang, J., Yang, R., Riquelme, M. A., et al. (2017). Biological Responses of Osteocytic Connexin 43 Hemichannels to Simulated Microgravity. J. Orthop. Res. 35, 1195-1202. doi:10.1002/jor.23224

Yamamoto, K., Imamura, H., and Ando, J. (2018). Shear Stress Augments Mitochondrial ATP Generation that Triggers ATP Release and Ca2+ Signaling in Vascular Endothelial Cells. Am. J. Physiol. Heart Circulatory Physiol. 315, H1477-H1485. doi:10.1152/ajpheart.00204.2018

Yu, Q., Li, J., Murrell, M. P., and Kim, T. (2018). Balance between Force Generation and Relaxation Leads to Pulsed Contraction of Actomyosin Networks. Biophysical J. 115 (10), 2003-2013. doi:10.1016/j.bpj.2018. 10.008

Conflict of Interest: The authors declare that the research was conducted in the absence of any commercial or financial relationships that could be construed as a potential conflict of interest.

Copyright (C) 2021 Kong, Quan, Tian, Zhou and Liu. This is an open-access article distributed under the terms of the Creative Commons Attribution License (CC BY). The use, distribution or reproduction in other forums is permitted, provided the original author(s) and the copyright owner(s) are credited and that the original publication in this journal is cited, in accordance with accepted academic practice. No use, distribution or reproduction is permitted which does not comply with these terms. 